\title{
Modelling Of Coal Transportation Technological Processes at Excavation
}

\author{
Konstantin Kopylov ${ }^{1}$, and Sergey Koubrin ${ }^{2}$ \\ ${ }^{1}$ JSC SUEK, 115054 53, bld. 7, Dubininskaya Str., Moscow, Russia \\ ${ }^{2}$ Institute of Problems of Comprehensive Exploitation of Mineral Resources RAS, 111020 4, \\ Kryukovskiy tupik, Moscow, Russia
}

\begin{abstract}
For efficient operation of a mining enterprise, the decisive role belongs to excavation areas forming volume of production and providing stability of support services. Taken engineering solutions to ensure permissible concentration of methane within working area depends on the nature of methane release (wall face, enclosing rocks, gob area, brokendown coal). Gas drainage operations from a working seam do not always provide reduction in methane emission to the required values and in these cases, effective and stable operation of an enterprise could be provided by the work of a shearer with an intensity that takes into account methane content in the developed seam, method of the working area preparation, ventilation scheme and vehicles characteristics. That is why modeling of broken-down coal transportation from the face, in order to determine the emitted methane, is an is an urgent task. The paper reviews issues of a mathematical model creation for coal transportation technological processes from the excavation area at the mine 'Polysaevskaya', JSC 'SUEKKuzbass'.
\end{abstract}

\section{Introduction}

The coal mining process by underground method refers to a dangerous type of human production activities. During it a man-made destruction of rock mass takes place (by mechanical, explosive and hydro-mechanical methods), necessary for issuance of rock mass raise. In the Russian Federation, the bulk of coal produced by underground mining is mechanized. In recent years, there is an intensification of mining operations, highperformance equipment is being introduced, load on mining and tunneling areas has increased by several times. Coal production in Russia in the period from January to June, 2016 had increased comparing to the same period in 2015 by $6 \%$ i.e. to 186.2 million tons, according to materials of The Central Dispatching Department of the Fuel and Energy Complex. In July Alexander Novak, Minister of Energy of Russia noted that Russia would increase coal production in 2016 by $4.4 \%$ comparing to the previous year, i.e. to 390 million tons. Production of the largest coal company JSC SUEK for this period had been 53.2 million tons of coal $(+14.5 \%$ to production during January - June, 2015). Load on coal face is up to $30 \mathrm{~K} \mathrm{t} /$ day, and in future, projects forecast increase in the load up to $40 \mathrm{~K}$ tons/day. Having such volumes of production, the energy saving factor is very important, which estimates decrease of energy resources used while maintaining beneficial effect of their use. 


\section{Material and Methods}

Coal transportation processes, their analysis and volume estimation were studied in relation to the mine Polysaevskaya, located in the Kemerovo region, the city of Polysaevo, colliery group Komsomolets, JSC SUEK-Kuzbass. Coal mining is carried out under the scheme 'mine - face' by one working area. They use Eickhoff SL-300 shearer, FFC-9 Glinik armored face conveyor, FSL-9 Glinik loader, FBL-10G GlinikB crusher.

There are various methods to determine maximum permissible load on face in methane containing mines [1-8]. They allow quite accurately determining the load on face under different mining and geological conditions, considering technological schemes of coal reserve development and ventilation schemes. However, complexity of calculations, availability of a set of coefficients, including empirical ones, which have different values along a face length does not let quickly obtain the result to determine the required speed for a shearer. Applying the available calculation methods and models for the purpose of operation, there are no current data regarding face gas surveys and actual efficiency of advance seam degassing.

Recently, The Multifunctional Safety Systems (MFSS) have been introduced at coal mines. The Concept of the Multifunctional Safety System Development for underground coal mining enterprises developed under coordination of JSC NC VostNII specify principles of mining enterprise management, goals, objectives, requirements, functions, organization and design of the MFSS. In accordance with the Concept, the MFSS is provided for effective management of an enterprise at a given level of safety (acceptable level of risk) for underground coal mining enterprises. The MFSS should identify the initial portents of emergency situation and provide preventive measures to escape development of the situation leading to a possibility of an accident.

Coal mining is complicated by its properties, characteristics and composition. First of all, presence of explosive methane gas in coal, releasing into the mining atmosphere during extraction of minerals, in combination with oxygen creates an explosive mixture. As per the Federal regulations and rules in terms of industrial safety, The Safety Rules at Coal Mines (with amendments of June 22, 2016) clause 166 and according to the Russian Federation Government Order of April 25, 2011 \#315 "Regarding admissible norms for explosive gases (methane) content in mine, coal seams and gobs at excess of which degassing is obligatory" clause 2 degassing of coal seam is a must, when natural methane content in a seam exceeds 13 cubic meters/t of dry ashless mass and ventilation cannot ensure the content of methane in the outgoing stream from mine workings less than 1 percent.

During operation of the coal face complex, distribution and isolation of methane depends on accepted ventilation scheme. Nonetheless the main sources of methane for any ventilation scheme remain, they are as follows: face baring, broken-down coal, wall rocks and gobs. The volume of methane emission is affected by its methane content, sorption and filtration properties of coal and the area of exposure. Over time, the intensity of gas emission decreases. Thus, if the effect of coal bed methane content on the methane release from coal has been studied to some extent, the sorption and filtration properties of coal, which define processes of methane movement in micro-pores, and its desorption from coal have not been studied.

\section{Results and Discussion}

In recent years, excavation areas have increased, and face length is already 200-400 meters. Therefore, at forecasting gas release, it is necessary to take into account the place of the methane source, the area of baring coal and the time of formation of exposure. In this regard, the correct choice of a program for operational management of mining technological processes, monitoring of technological operations fulfillment for the timely detection of 
deviations from the selected mode, adjustment of the established current modes of operation of technological processes and development, if necessary, measures aimed at reducing the risk of accidents is very important. The prospective solution to solve the problem is the use of modeling methods. The developed models of technological processes for mining enterprise will allow to plan production and perform decision support at implementation of operational management to identify negative trends in techno-genic environment, and early warning signs of emergency, to evaluate risks of possible accidents and downtime, to plan preventive measures to neutralize or minimize any negative effects, improve the structure of production teams in terms of their operations. During the working stroke at the movement of shearer the destruction of the coal seam is made by executive body- shearer cutting drum.

Coal-mining enterprises more frequently apply technology of shearer operating in a shuttle way with an oblique-in arrival at the interface with a shaft, consisting of five stages (gate of the face conveyor on the oblique-in arrival, notch oblique arrival, cleaning the notch with subsequent alignment of the scraper conveyor, and the excavation of the upper and lower ledges). Thus, the movement of shearer at working stroke along the face line is carried out with a speed $V_{s h}=V_{s h}(t)$. Its location is defined as a coordinate $\mathrm{x}(\mathrm{t})$. Then the equation of its move along the face looks like $\frac{d x}{d t}=V_{s h}(t)$. It should be taken into consideration, that a shearer operator moves shearer in relation to the section of the roof support. So, in this case shearer speed depends on its placement $V_{s h}(x)$. Therefore, the equation of the shearer movement along the face as $\frac{d x}{d t}=V_{s h}(t)=V_{s h}(x)=V_{s h}(x(t))$ is correct.

Being at the point $x$ shearer moves at speed $V_{\text {sh }}$ for a period of time $\mathrm{dt}$ and broken-down coal $\mathrm{dV}$ determined by the ratio $d V=h m V_{s h}$, where: $\mathrm{h}$ - the length of the shearer flight, $\mathrm{m}$ - capacity of a seam. Considering the volume weight of coal per unit of time, shearer break down coal by weight $d M=\gamma h m V_{k} d t$, where: $\gamma$ - the volumetric weight of coal.

The broken-down coal falls on the chain-and-flight conveyor and is described by some function $\varphi=\varphi(x)$. Moreover, due to movement of the chain-and-flight conveyor and movement of shearer in general, the loading on the chain-and-flight conveyor changes in time and space $\varphi=\varphi(x, t)$. The increase in volume of coal as a result of breaking-down of it by shearer (assuming that all the broken-down coal is moved to the scraper conveyor and neglecting the shearer dimensions) will be written by the expression $\varphi=\varphi\left(x_{k}, t\right)=$ $\varphi\left(x_{k i}, t_{i}\right)+d M=\varphi\left(x_{i}, t_{i}\right)+\gamma h m V_{k} d t$. In addition, the chain-and-flight conveyor moves at a speed $V_{s k}$. Speed of the most face (chain-and-flight) conveyors is constant and cannot be changed $\left(V_{s k}=\right.$ const $)$.

Therefore, the function is converted $\varphi(x, t)$, which is defined by the shift operation and is described by the expression $\varphi\left(x_{i}, t+d t\right)=\varphi\left(x_{i}-V_{s k} d t, t\right)$ for the entire face area (i.e. for the all $x_{0} \leq x_{i} \leq x_{n}, x_{0}$ - the coordinate of the beginning of the chain-and-flight conveyor, located at the lower entry in the place where reloading of coal from the chain-andflight conveyor to a loader takes place, $x_{n}$ - the coordinate of the end of the chain-and-flight conveyor, located at the upper entry). In this case, the part of the conveyor, which is located at the upper entry, and is a section that appeared in the time interval dt remains empty $\varphi(x, t)=\varphi\left(x_{n} \div x_{n}-V_{s k} d t, t+d t\right)=0$.

Coal that was on the chain-and-flight conveyor at the bottom of the entry is overloaded by a loader connected to a crusher. This coal is $\varphi_{\text {out }}(x, t)=\varphi\left(x_{1} \div x_{1}+V_{s k} d t, t\right)$. A loader, crushing complex, and belt conveyor work similar to a chain-and flight conveyor as a flow device for rock mass movement.

Consequently, relations describing the process of movement of a shearer, rock mass, utilizing the specified process equipment are as follows:

shearer movement along face:

$$
\frac{d x}{d t}=V_{k}(t)
$$


coal:

$$
\left\{\begin{array}{c}
\varphi_{s k}\left(x_{i}, t_{i}\right)+d M=\varphi_{s k}\left(x_{i}, t_{i}\right)+\gamma h m V_{k} d t\left(x_{i}=x_{k}\right) \\
\varphi_{p}\left(x_{i}, t_{i}\right)+d M=\varphi_{p}\left(x_{n} \div x_{n}-V_{p} d t, t_{i}\right)=\varphi_{s k}\left(x_{1} \div x_{1}+V_{s k} d t, t_{i}\right) \frac{V_{s k}}{V_{p}} \\
\varphi_{d}\left(x_{i}, t_{i}\right)+d M=\varphi_{d}\left(x_{n} \div x_{n}-V_{d} d t, t_{i}\right)=\varphi_{p}\left(x_{1} \div x_{1}+V_{p} d t, t_{i}\right) \frac{V_{p}}{V_{d}} \\
\varphi_{l k}\left(x_{i}, t_{i}\right)+d M=\varphi_{l k}\left(x_{n} \div x_{n}-V_{l k} d t, t_{i}\right)=\varphi_{d}\left(x_{1} \div x_{1}+V_{d} d t, t_{i}\right) \frac{V_{d}}{V_{k l}}
\end{array}\right.
$$

In the ratio (4.1) and subsequently the following notation: the sk index - a chain-andflight conveyor; the $\mathrm{p}$ index is a loader; the $\mathrm{d}$ index is a crusher; the $\mathrm{lk}$ index is a belt conveyor.

The ratios describing the movement of coal on technological equipment have the form:

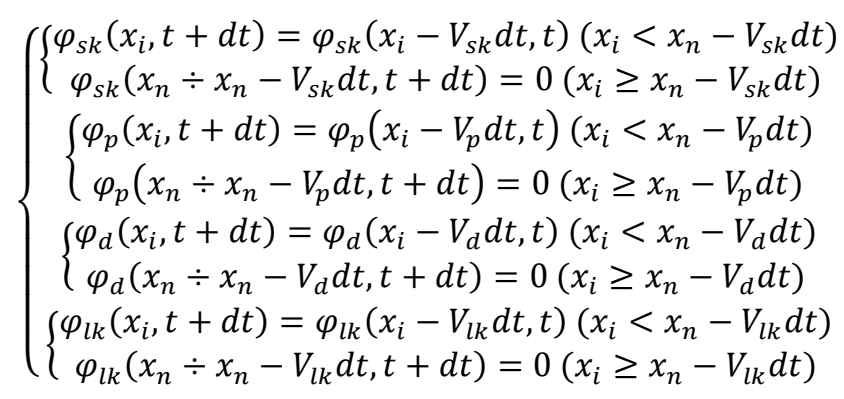

The ratios describing movement (reloading) of coal from one to another technological equipment:

$$
\left\{\begin{array}{c}
\varphi_{\text {out } \rightarrow p}(x, t)=\varphi_{s k}\left(x_{1} \div x_{1}+V_{s k} d t, t\right) \\
\varphi_{\text {out } \rightarrow d}(x, t)=\varphi_{p}\left(x_{1} \div x_{1}+V_{p} d t, t\right) \\
\varphi_{\text {out } \rightarrow l k}(x, t)=\varphi_{d}\left(x_{1} \div x_{1}+V_{d} d t, t\right) \\
\varphi_{\text {out }}(x, t)=\varphi_{l k}\left(x_{1} \div x_{1}+V_{l k} d t, t\right)
\end{array}\right.
$$

Based on the obtained ratios, the modeling of the technological process of breaking and transporting coal was carried out. Technological process of running of working pass by a shearer in terms of restrictions related to the emissions from the broken coal was considered. It was assumed that the volume of methane released from the broken-down coal is proportional to the volume of the broken-down coal. Changes in intensity of methane release over time were not taken into consideration, due to the time of the broken coal spent in the face did not exceed $2-3$ minutes. Shearer feed speed as of $6 \mathrm{~m} / \mathrm{min}$ was defined by the technological passport of reserves excavation on site \# 17-49 of the seam Breevskiy at Polysaevskaya mine. The results of the modeling of the technological process of coal mining and transportation in the face showed (Fig. 1) that at the beginning of shear there is no coal in the face. After the beginning of the sharer movement, coal volume begins to grow sharply and fills first the entire loader, then the segment of the belt conveyor to the air hole. Upon filling the segment of the conveyor to the air hole, the rate of increase of coal volume in the face goes down. The increase in the coal volume in the face during this period is due to the fact that the shearer is gradually removed from the face and the length of the loaded part of the chain-and-flight conveyor increases. The increase reaches its maximum at the moment when the shearer comes to the upper junction and characterizes the movement of the brokendown coal. Using a one-way operation scheme for a shearer, the shearer runs at idle speed down at the maximum possible speed, while the volume of coal on the chain-and-flight and 
belt conveyors and the loader is rapidly reduced. In order to reach bottom point of the face a shearer requires $900 \mathrm{sec}$. (15 minutes) at a speed of $20 \mathrm{~m} / \mathrm{min}$, and coal on the chain-andflight conveyor, loader and on the segment of the belt conveyor to the air hole will leave the face in 500 seconds ( 8.3 minutes). That is, by the beginning of the next shear and subsequent shear cut, there will no coal in the face. The analysis of the load schedule for the loader, chain-and-flight and belt conveyors showed that it is not even and reaches the maximum volume, accepted by the project, only at one point corresponding to the position of a shearer at the top of the face.

The volume of coal on loader (blue), chain-and-flight conveyor (black), belt conveyor (green), total (red) at the feed speed $6 \mathrm{~m} / \mathrm{min}$.

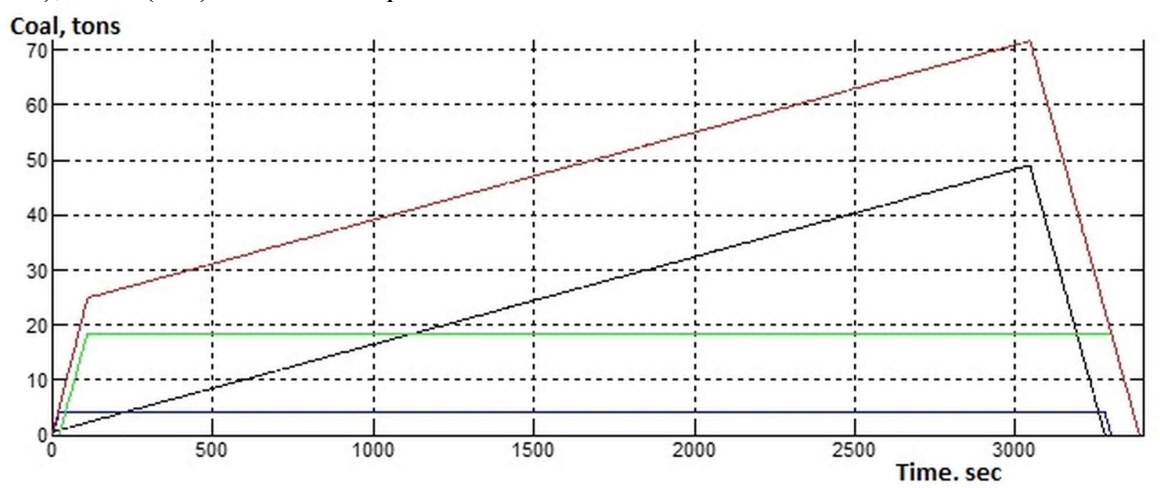

Fig. 1. Volume of coal in the face \# 17-49.

Using this mode of the shearer operation, when the speed at its movement up decreases linearly from the maximum (at the bottom of the face) to the minimum, equal to $50 \%$ of the maximum (at the top of the face), we obtain the load of the technological equipment of the fully-mechanized longwall by coal, see Fig. 2 (shearer idle run down the face is not shown).

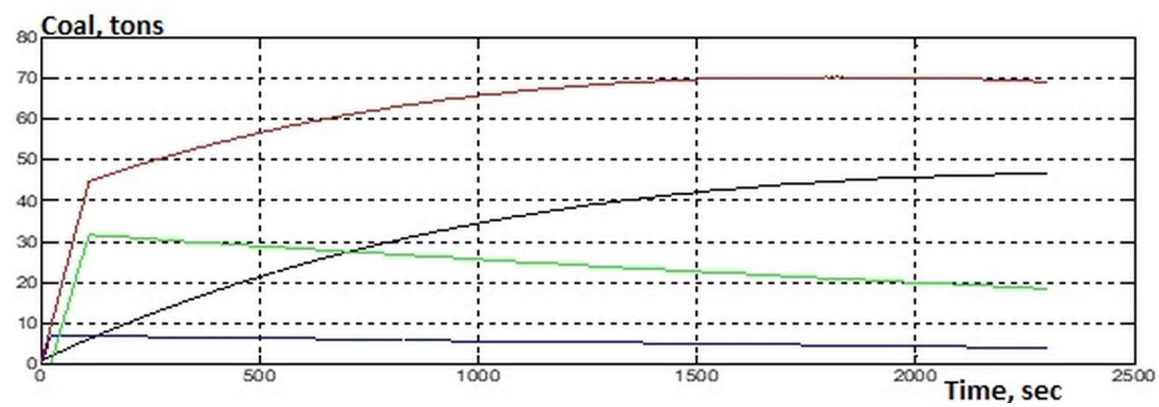

Fig. 2. Volume of coal at the mode of a shearer, when the speed $11 \mathrm{~m} / \mathrm{min}$ decreases linearly to $5.5 \mathrm{~m}$ $/ \mathrm{min}$.

Thus, it is possible to increase the volume of produced coal by establishing such a mode for changing feed speed of a shearer during the working course, in which the feed speed of a shearer along the face will change.

\section{Conclusion}

In both reviewed modes for control of the mechanized complex: with a constant shearer feed speed $(6 \mathrm{~m} / \mathrm{min}$.) and with a variable shearer feed speed (decreases linearly from $11 \mathrm{~m} / \mathrm{min}$. 
to $5.5 \mathrm{~m} / \mathrm{min}$.), the volume of the broken-down coal is the same, only the time of the working stroke varies.

In the first version with a constant shearer feed speed, it is $3040 \mathrm{sec}$. (50.7 minutes), in the second version with a shearer variable feed speed $-2305 \mathrm{sec}$. (38.4 minutes). Then the intensity of the coal breaking-down for the first version (with a constant shearer feed rate) would be $14.61 \mathrm{t} / \mathrm{min}$, and the second (with a variable shearer feed speed) - of $19.26 \mathrm{t} / \mathrm{min}$. Thus, coal production build-up per unit of time per stroke will be 31.8 per cent.

The volume of coal on loader (blue), chain-and-flight conveyor (black), belt conveyor (green), total (red) at the feed speed $11-5.5 \mathrm{~m} / \mathrm{min}$.

\section{References}

1. V.N. Zakharov, S.S. Kubrin, V.S. Zaburdiaev, GIAB, 6, 78-84 (2015)

2. A.D. Ruban, V.B. Artemiev, V.S. Zaburdiaev, G.S. Zaburdiaev, Yu.F. Rudenko, The problems of ensuring high productivity of mine faces in methane-mining mines (Publishing House LLC "Moscow Publishing House", Moscow, 2009)

3. S.S. Kubrin, S.N. Reshetnyak, A.M. Bondarenko, Mining Informational and analytical bulletin (scientific and technical journal), 1, 528-534 (2018)

4. Federal rules and regulations in the field of industrial safety "Safety Rules in Coal Mines". Rostechnadzor Order No. 550 of November 19, 2013 (registered by the Ministry of Justice of Russia on December 31, 2013, registration No. 30961) (RF Government, Moscow, 2013)

5. S.S. Kubrin, An automated system for managing mining production, as a platform for integrating technological stages and operations into a single technological process. Mountain information and analytical bulletin (Mining, Moscow, 2016)

6. S.S. Kubrin, S.G. Chudinov, A.V. Lander, Mining information and analytical bulletin, 8, 225-228 (2005)

7. K.N. Trubetskoi, Mining. Terminological dictionary (Mining, Moscow, 2016)

8. Regulation on air-gas control in coal mines. Order of Rostekhnadzor of 01.12.2011 No 678 (registered by the Ministry of Justice of Russia on 29.12.2011, registration No. 22812) (RF Government, Moscow, 2013) 